https://doi.org/10.1590/198053145589

\title{
BLACK LIVES MATTER NOS CURRÍCULOS? IMPRENSA NEGRA E ANTIRRACISMO EM PERSPECTIVA TRANSNACIONAL
}

\author{
Amilcar Araujo Pereira'
}

\section{Resumo}

O presente artigo discute alguns aspectos históricos das lutas antirracistas voltadas para a área da educação da população negra, em especial para o ensino de História, nos contextos dos Estados Unidos (EUA) e do Brasil, a partir principalmente da análise de artigos e reportagens publicadas em jornais da imprensa negra estadunidense e brasileira. Por meio dos exemplos aqui apresentados e analisados, é possível perceber como as populações negras têm produzido diferentes estratégias e têm obtido diferentes resultados na luta antirracista por educação e pela afirmação de sua humanidade ao longo da história do Brasil e dos EUA.

RACISMO • IMPRENSA NEGRA • EDUCAÇÃO • CURRÍCULO

\section{BLACK LIVES MATTER IN CURRICULA? BLACK PRESS AND ANTI-RACISM IN TRANSNATIONAL PERSPECTIVE}

\section{Abstract}

This article discusses some historical aspects of the anti-racist struggles focusing the Education of the black population, especially the History teaching, in the United States' and Brazil's contexts, mainly from the analysis of articles and reports published in newspapers of the American and Brazilian black press. Through the examples presented and analyzed here, it is possible to see how Black populations have produced different strategies and have obtained different results in the anti-racist struggle for education and the affirmation of their humanity throughout the history of Brazil and of the United States.

RACISM • BLACK PRESS • EDUCATION • CURRICULUM 


\section{BLACK LIVES MATTER DANS LES CURRICULA? LA PRESSE NOIRE ET L'ANTIRACISME, UNE PERSPECTIVE TRANSNATIONALE}

\section{Résumé}

Cet article discute certains aspects historiques des luttes antiracistes à propos de l'éducation des noirs et, plus particulièrement, celui de l'enseignement de l'histoire aux États-Unis et au Brésil. L'analyse s'appuie principalement sur des articles et des reportages publiés dans les journaux de la presse noire dans ces deux pays. À travers les exemples présentés et analysés, il est possible de percevoir comment les populations noires ont, tout au long de l'histoire du Brésil et des États-Unis, développé différentes stratégies et obtenu différents résultats pour lutter contre le racisme en éducation et affirmer leur humanité.

\section{RACISME • PRESSE NOIRE • ÉDUCATION • CURRICULUM}

\section{BLACK LIVES MATTER EN LOS CURRÍCULOS? PRENSA NEGRA Y ANTIRRACISMO EN PERSPECTIVA TRANSNACIONAL}

\section{Resumen}

El presente artículo discute algunos aspectos históricos de las luchas antirracistas dirigidas al área de la educación de la población negra, en especial para la enseñanza de Historia, en los contextos de Estados Unidos y Brasil, a partir principalmente del análisis de artículos y reportajes publicados en los periódicos de la prensa negra estadounidense y brasileña. Por medio de los ejemplos aquí presentados y analizados es posible percibir cómo las poblaciones negras han producido diferentes estrategias y han obtenido diferentes resultados en la lucha antirracista por educación y por la afirmación de su humanidad a lo largo de la historia de Brasil y Estados Unidos.

\section{RACISMO • PRENSA NEGRA • EDUCACIÓN • PLAN DE ESTUDIOS}


Nossa história

A nossa não chegou em capítulos

nem de menor a maior

como costuma acontecer,

não nos chegou desde o começo, desde o berço,

desde os primeiros dias da escola,

não nos apareceu nos livros

ou nas surpresas dos cereais ou essas coisas.

Comportou-se cruel e egoísta conosco,

manteve-se oculta como uma ladra,

como quem se resiste a dar luz... e compartilhar.

Ela nos chegou em línguas desconhecidas,

fragmentada, chegou-nos interpretada pelos inimigos,

com seus rostos e suas verdades,

foi-nos entregue suja... vazia,

despedaçada, chegou-nos em farrapos,

descalça, metralhada,

e nós a acolhemos humilhada.

Foi necessário que saíssemos

como valentes guerreiras a recuperá-la,

a limpar suas lágrimas,

suas mãos, a vesti-la de novo,

enchê-la de orgulho, lavar seus joelhos; e quando ficou pronta a levamos pro sol,

e nossa história agora brilha bonita,

resplandecente, forte,

e caminha desde então

com o peito erguido e a cabeça alta.

Shirley Campbell Barr

S "VIDAS NEGRAS IMPORTAM" REALMENTE NA EDUCAÇÃO, NOS CURRÍCULOS E NO ensino de História em países tão diferentes como os Estados Unidos (EUA) e o Brasil, por exemplo? O objetivo deste artigo é discutir essa questão, analisando aspectos históricos das lutas antirracistas nesses dois países, especialmente as lutas em torno do currículo e do ensino de História, a partir de uma pespectiva transnacional embasada nas pesquisas realizadas pelo autor, nos últimos anos, em jornais históricos da imprensa negra nos Estados Unidos e no Brasil. ${ }^{2}$

1 Shirley Campbell Barr é antropóloga, militante e poeta afro-costarriquenha, descendente de jamaicanos, especializada em feminismo africano. O poema citado foi publicado em: Barr (2013, p. 66-67), com tradução para o português, inédita, de Bethania Guerra de Lemos.

2 A pesquisa realizada em Nova lorque foi financiada por meio do convênio Capes-Fulbright, na forma de uma bolsa de pós-doutorado, realizado pelo autor na Columbia University, em Nova lorque, nos EUA entre 2015 e 2016. A pesquisa realizada no Brasil conta com o auxílio financeiro do Conselho Nacional de Desenvolvimento Científico e Tecnológico (CNPq), por meio do edital Universal 2016. 
O movimento Black Lives Matter ${ }^{3}$ surgiu em 2012 na luta contra a violência policial e o assassinato de jovens negros nos EUA, afirmando sobretudo a humanidade das populações negras. A violência policial, que mata jovens negros em números alarmantes, desumaniza. Da mesma forma que foram desumanizados os africanos escravizados e seus descendentes desde sua chegada forçada nas Américas a partir do século XVI. Essa desumanização se deu e ainda se dá de várias formas, inclusive por meio da violência, que é o apagamento ou a invisibilização das memórias e histórias das populações negras nos currículos e nas escolas. Vários autores já discutiram as relações diretas entre memória, história e identidade (POLLAK, 1992; LE GOFF, 1984), bem como a importância dos currículos escolares nessas discussões (SILVA, 2007; MOREIRA e SILVA, 2002).

Segundo diversos autores, ${ }^{4}$ a História como disciplina escolar no Brasil efetivou-se com a criação do Colégio D. Pedro II em 1837, e tinha como objetivo formar os filhos da nobreza da Corte do Rio de Janeiro e prepará-los para o exercício do poder. No mesmo ano, foi também criado o Instituto Histórico e Geográfico Brasileiro (IHGB), instituição à qual cabia construir a genealogia nacional, no sentido de dar uma identidade à nação brasileira. Os membros do IHGB eram professores do Colégio D. Pedro II, e suas resoluções sobre a História afetavam diretamente o trabalho na escola. Tratava-se então de um conhecimento escolar organizado para a formação das elites encarregadas de dirigir a nação, e não havia interesse dessas elites em incluir em seus projetos políticos a participação de camadas populares, descendentes de africanos ou indígenas, por exemplo. Iniciava-se, portanto, naquele período, um processo de construção de um ensino de História absolutamente eurocêntrico, que se tornaria ao longo do tempo uma verdadeira tradição na educação no Brasil. A identidade nacional que se disseminava por meio das escolas tinha uma relação genealógica com o mundo europeu, já que a descoberta do Brasil pela monarquia portuguesa correspondia ao nascimento de uma nação branca, europeia e cristã. Segundo Circe Bittencourt, nos programas curriculares do Colégio D. Pedro II, que servia como modelo nacional, predominava a história universal em detrimento de um ensino de História do Brasil:

De maneira aparentemente paradoxal, a formação das futuras elites não necessitava de um maior conhecimento sobre - Brasil, sua história, seu território. Ser brasileiro para essas gerações era ser branco e pertencer à cultura europeia. (2007, p. 36)

Ao longo do século XX, ainda pautado por uma historiografia eurocêntrica sob a ótica francesa, o ensino de História, a partir da Reforma de Francisco Campos, em 1931, mantinha o Brasil, assim como os demais países da América Latina, como simples apêndices de uma história da civilização criada pela raça

3 Para maiores informações sobre o movimento, ver: http://blacklivesmatter.com/about/. Acesso em: 19 maio 2018.

4 Ver, entre outros, Abud (2007), Bittencourt (2004) e Nadai (1992/1993). 
branca (BITTENCOURT, 2007, p. 41). Somente em meados do século XX o contexto da produção historiográfica possibilitou novas análises sobre o Brasil, como a realizada em Raízes do Brasil, de Sérgio Buarque de Hollanda (1995). Obra que iniciava e trazia para o cenário nacional personagens pouco estudados, como os escravos, os colonos pobres, os operários, etc. Entretanto “os conteúdos de História do Brasil e, até mesmo, de História da América foram ampliados, sem significar, porém, uma mudança quanto ao predomínio de uma história calcada no modelo europeu e civilizatório" (BITTENCOURT, 2007, p. 43).

A violência e o racismo contra a população negra na África e na diáspora, especialmente com o imperialismo e o colonialismo marcantes, sobretudo a partir do século XIX, ${ }^{5}$ continuam sendo uma constante na história das Américas (FANON, 2005); assim como têm sido constantes as lutas antirracistas por toda a diáspora. Essas lutas também têm se dado de maneira potente, pelo mundo afora, no âmbito do currículo, considerado aqui como uma arena cultural de disputas, ${ }^{6}$ e do ensino de História. Como já foi demonstrado pela historiografia contemporânea, é evidente o protagonismo da população negra na luta pela "reavaliação do papel do negro na história do Brasil” (PEREIRA, 2012, p. 113) ou pela nossa história, como podemos observar na poesia que abre este artigo, escrita há poucos anos por uma poeta e militante negra da Costa Rica. A referida poesia também evidencia como a luta pela recuperação das histórias das populações negras, entendendo a sua importância para a educação - não somente, mas especialmente de negros e negras pelo mundo -, é uma característica marcante dos movimentos negros na diáspora africana. Essa luta não pode ser vista como restrita a um estado nacional, ao contrário, posto que encontramos em diversas fontes históricas muitas evidências de que movimentos da população negra, como valentes guerreiras, têm produzido diferentes estratégias de luta antirracista por educação e pela afirmação de sua humanidade ao longo da história. Essas ações e informações produzidas circulam, tornam-se referenciais e inspiram a continuidade, e também a transformação dessas lutas antirracistas pela diáspora.

Um bom exemplo é o caso do editor e cofundador do primeiro jornal da imprensa negra norte-americana, o Freedom's Journal, reverendo Samuel Cornish (1795-1858), nascido livre, filho de um casal de negros libertos em Delaware, nos Estados Unidos, que dizia já no editorial do primeiro número de seu recém-criado jornal, publicado em 16 de março de 1827: “Queremos defender a nossa própria causa. Há muito que os outros têm falado por nós. Por muito tempo o público foi enganado por falsas declarações sobre as coisas que nos preocupam profundamente". ${ }^{7}$ Segundo James Allen, em artigo publicado em 12 de junho de 1971, em outro jornal da imprensa negra norte-americana, o New York Amsterdam News, Cornish propôs em várias ocasiões a criação de uma escola (que posteriormente

5 Sobre a ideia de raça e seus impactos na formação da sociedade brasileira, ver Pereira (2013).

6 Ver Moreira (2002).

7 As traduções aqui presentes foram realizadas pelo autor do artigo.

No original: "We wish to plead our cause. Too long have other spoken for us. Too long has the publick been deceived by misrepresentations, in things which concern us dearly." 
seria equivalente a uma faculdade) para educar jovens negros norte-americanos naquele período, ainda em meio à escravidão. Em 1831, numa convenção de líderes negros cristãos realizada na Filadélfia entre 6 e 11 de junho, Cornish, juntamente com outros líderes religiosos negros e com apoio, inclusive financeiro, de abolicionistas brancos, adotou uma resolução que determinava a criação do que seria a primeira faculdade "para a instrução de jovens homens de cor no sistema manual de trabalho, pelo qual os filhos dos pobres poderão receber uma educação regular clássica, assim como os filhos dos irmãos mais bem-sucedidos” (ALLEN, 1971, tradução nossa). ${ }^{8}$ Ainda segundo James Allen, ficou então decidido naquela convenção que essa faculdade seria construída em New Haven, no estado de Connecticut, em função da "reputação daquela comunidade pelo esclarecimento e boa vontade para com os negros", ${ }^{9}$ bem como pela proximidade da então Faculdade de Yale, que se tornava, já naquela na época, um importante centro de produção de conhecimentos nos Estados Unidos. Entretanto, mesmo dispondo de recursos para a sua criação, a faculdade para jovens negros não foi criada em New Haven. Em setembro de 1831, quando foi tornado público o plano de construção, vários professores de Yale, doadores, alunos e ex-alunos, especialmente os sulistas, estabeleceram uma forte oposição ao projeto, afirmando que seria ruim para a Yale ter uma faculdade para negros nas suas redondezas. Com isso, o prefeito acabou proibindo, com apoio do City Council, a criação dessa faculdade para negros em New Haven ainda em 1831, com a seguinte resolução: “O estabelecimento de uma faculdade para educar pessoas de cor é incompatível com a prosperidade, senão com a própria existência, das atuais instituições de conhecimento, e será destrutivo para os melhores interesses da cidade" (ALLEN, 1971). ${ }^{10}$

Naquela mesma década, New Haven tornaria-se uma cidade famosa nos Estados Unidos por ter sido o local onde, entre 1839 e 1841, ficaram presos os africanos escravizados que se revoltaram, mataram o capitão e tomaram o navio Amistad, que tinha saído de Cuba cerca de dois meses antes. O caso do navio Amistad tornou-se um símbolo das lutas dos negros contra a escravidão nos Estados Unidos. ${ }^{11}$

Inspirados em tentativas anteriores, como a de Samuel Cornish e seus parceiros em 1831, na segunda metade do século XIX, especialmente com a abolição da escravidão e o período da Reconstrução, ${ }^{12}$ após 1865 , homens e mulheres negros criaram várias escolas e faculdades para negros naquele país. Principalmente a partir da fundação, no estado do Alabama em 1881, do Tuskegee Institute, que,

8 No original: "for the instruction of young men of color, on the manual labor system by which the children of the poor may receive a regular classical education, as well those of their more opulent brethren..."

9 No original: "the reputation of the community for the enlightment and good will toward black people..."

10 No original: "the establishment of a College to educate the Colored population is incompatible with the prosperity if not the existence of the presente institutions of learning, and will be destructive of the best intersts of the City." A primeira universidade historicamente negra a ser criada nos EUA foi a Cheyney University of Pennsylvania, fundada em 1837.

11 Uma versão dessa história foi contada no filme Amistad, dirigido por Steven Spielberg e lançado em 1997.

12 A Reconstrução (1865-1877) é como é chamado o período posterior à Guerra Civil norte-americana (1861-1865), quando os vencedores, do Norte, direcionavam seus esforços para a abolição da escravatura, para a eliminação da Confederação dos Estados do Sul e para a reconstrução do país e da Constituição dos Estados Unidos. 
sob a liderança de Booker T. Washington, ${ }^{13}$ posteriormente se tornaria uma importante universidade negra no Sul dos Estados Unidos.

No Brasil há várias histórias, muitas infelizmente ainda pouco conhecidas e estudadas, de criação de jornais da imprensa negra e de escolas para educar a população negra desde meados do século XIX. A criação, no Rio de Janeiro, do jornal $O$ homem de cor, ainda em 1833, somente seis anos após a criação do primeiro jornal da imprensa negra norte-americana, pelo editor negro Francisco de Paula Brito - um dos pioneiros editores no Brasil, e o primeiro a publicar um trabalho do escritor afro-brasileiro Machado de Assis -, é um importante exemplo. Bem como a criação de uma escola de primeiras letras em 1853 por um professor declarado preto, Pretextato Passos da Silva, para atender um público de meninos pretos e pardos na Freguesia de Santíssimo Sacramento, freguesia urbana do Rio de Janeiro. Segundo Higor Figueira Ferreira, em sua dissertação de mestrado, a criação da escola teria sido resultado da ação dos pais desses meninos em prol de uma educação que atendesse mais efetivamente seus filhos (FERREIRA, 2013). Estratégia semelhante, por outro lado, em terras brasileiras, tornou-se rara após a abolição da escravidão. Sob a égide da ideia de igualdade republicana no Brasil, as escolas criadas por negros e exclusivamente para negros esteve restrita a algumas organizações do movimento negro, como a Frente Negra Brasileira (FNB). Essa organização, criada em São Paulo em 1931, talvez seja um dos maiores exemplos de circulação de referenciais para a luta antirracista nas Américas, também na área da Educação. A FNB criou, assim como Samuel Cornish nos EUA, cerca de um século antes, o seu próprio jornal, o A voz da raça, e criou também, inspirada em Booker T. Washington e outros líderes negros norte-americanos, escolas para educar a população negra tanto na sede da organização em São Paulo como em suas representações em vários estados brasileiros, como o Rio de Janeiro, a Bahia e Minas Gerais. A FNB tornou-se um partido político em 1936, depois de uma longa batalha jurídica para poder disputar as eleições de 1937. Mas acabou fechada, assim como todas as outras organizações políticas brasileiras, em novembro de 1937, depois do golpe de estado e da implantação da ditadura do Estado Novo de Getúlio Vargas. O que poucos brasileiros sabem, no entanto, é que essa mesma FNB, que reunia milhares de membros associados e tinha força política considerável, ${ }^{14}$ também serviu de referencial e inspiração, ainda na década de 1930, para a luta por direitos civis e sociais para a população negra nos EUA e na diáspora. ${ }^{15}$

Como já foi dito em outros momentos, a circulação de referenciais pela diáspora africana, no que diz respeito à luta antirracista, é algo fundamental para a compreensão das estratégias e ações realizadas por negros na luta por educação e no âmbito dos currículos de História (PEREIRA, 2013). Nesse sentido, entendo que o cientista político Michael Hanchard (2002) tem razão quando fala da

\footnotetext{
13 Booker T. Washington (1856-1915) foi um ex-escravo liberto que se tornou um dos mais importantes educadores norte-americanos e uma das principais lideranças negras do país no final do século XIX.

14 Ver Cunha (1995/1996).

15 Ver o terceiro capítulo do livro O Mundo Negro: relações raciais e a constituição do movimento negro contemporâneo no Brasil (PEREIRA, 2013).
} 
importância de se pensarem os movimentos negros como reflexos da política negra transnacional e não como entidades restritas aos seus respectivos Estados-nação. Para ele a circulação de referenciais pelo mundo é fundamental para poder compreender as configurações das lutas contra o racismo em diferentes lugares e momentos da história. Segundo Michael Hanchard, o desafio específico para muitos acadêmicos brasileiros e brasilianistas, ao considerar os movimentos sociais negros brasileiros como faceta da política negra transnacional, está em ver a participação de organizações tais como a FNB:

Não só como forma de apresentação de história nacional e regional, mas também como faceta integral de uma comunidade multinacional, multilíngue, ideológica e culturalmente plural - uma comunidade imaginada, se quiserem, mas não necessariamente limitada por um país territorial singular. (HANCHARD, 2002, p. 88-89)

\title{
AS LUTAS ANTIRRACISTAS EM TORNO DOS CURRÍCULOS DE HISTÓRIA
}

\begin{abstract}
Reconstruir o discurso da diferença cultural exige não apenas uma mudança de conteúdos e símbolos culturais; uma substituição dentro da mesma moldura temporal de representação nunca é adequada. Isto demanda uma revisão radical da temporalidade social na qual histórias emergentes possam ser escritas; demanda também a rearticulação do "signo" no qual se possam inscrever identidades culturais. E a contingência como tempo significante de estratégias contra-hegemônicas não é uma celebração da "falta" ou do "excesso", ou uma série autoperpetuadora de ontologias negativas. Esse "indeterminismo" é a marca do espaço conflituoso mas produtivo, no qual a arbitrariedade do signo de significação cultural emerge no interior das fronteiras reguladas do discurso social. (BHABHA, 1998, p. 240)
\end{abstract}

As lutas antirracistas em torno dos currículos, especialmente da disciplina História, utilizando estratégias contra-hegemônicas, são evidentes em diversas fontes históricas, tanto no Brasil quanto nos EUA. Essas lutas, em meio às contingências e indeterminismos, lidando com as possibilidades construídas com poucos recursos e muitas dificuldades, têm produzido resultados importantes na história da educação nos dois países, como se verá adiante. Uma importante contribuição para a construção da pesquisa realizada e deste artigo é a formulação teórica de Amilcar Cabral, que, durante a luta por libertação do colonialismo português na Guiné-Bissau e em Cabo Verde, afirmava que essa luta não 
seria apenas um "fato cultural mas também um fator de cultura” (CABRAL, 1974, p. 137). A luta pela libertação (um fato cultural que também construía, que produzia cultura) e a descolonização no sentido mais amplo se davam fundamentalmente por meio da educação do "povo africano da Guiné e Cabo Verde”, na perspectiva de Cabral.

São muitas as lutas realizadas pelas populações negras historicamente no sentido de produzir espaços de enunciação das diferenças (BHABHA, 1998) nas sociedades e nos currículos, contrapondo-se às hierarquizações e desigualdades evidenciadas, seja em sociedades estruturalmente racistas seja em currículos eurocêntricos, no Brasil e nos EUA. Ao longo das pesquisas realizadas por diversos autores nos últimos anos, tem-se encontrado evidências dessas lutas em diversas fontes históricas, especialmente nos jornais da imprensa negra nos EUA e no Brasil, principalmente a partir do início do século XX, criados para contar "histórias emergentes" que pudessem provocar na sociedade e também na educação, como diz Bhabha, inspirado em Fanon, a importante "instabilidade produtiva da mudança cultural” (BHABHA, 1998, p. 68).

É importante ressaltar que não se pode separar as lutas no âmbito do currículo escolar das contingências e das lutas sociais. Um bom exemplo, nesse sentido, é a afirmação de Willian Watkins, ao analisar as lutas das populações negras norte-americanas na área da educação:

\section{[...] o currículo tem sido uma característica definidora da educação negra [...] A batalha sobre o que os afro-america- nos aprendem tem sido longa e inextricavelmente ligada à política nacional, aos direitos civis, à economia do trabalho e à justiça social. (2001, p. 40)16}

No livro The Struggle for Black History [A luta pela História Negra], publicado em 2008, Abul Pitre, Ruth Ray e Esrom Pitre, discutindo a construção do que eles chamam de uma "pedagogia crítica negra" no período contemporâneo nos Estados Unidos, afirmam que "estudantes afro-americanos, pais e grupos comunitários estão liderando a pressão por um currículo que reflita a experiência de africanos e afro-americanos". ${ }^{17}$ E continuam, ao citar outro autor, dizendo que a luta para implementar um currículo que reflita essas experiências da população negra “é provável que continue, será feroz e, às vezes, se tornará feia e perniciosa. Vai tomar diversas formas, expressões e contornos"18 (BANKS, 2002, p. 27, ${ }^{19}$ apud PITRE; RAY; PITRE, 2008, p. 3). O fato é que essa luta, ainda muito presente

\footnotetext{
16 No original: "Curriculum has been a defining feature of black education. [...] The battle over what African Americans learn has been long-standing and inextricably connected to national politics, civil rights, labor economics, and social justice."

17 No original: "African American students, parents, and Community groups are leading the push for curriculum that reflects the experience of Africans and African Americans."

18 No original: "is likely to continue, will be fierce and will at times become ugly and pernicious. It will take diverse forms, expressions, and shapes."

19 BANKS, J. An introduction to multicultural education. Boston: Allyn and Bacon, 2002.
} 
naquele contexto nacional atualmente, é bem antiga e já teve diferentes contornos, alguns dos quais podem ser identificados, por exemplo, em reportagens e artigos publicados na imprensa negra dos EUA.

Ao analisar os arquivos de diversos jornais dessa imprensa negra nos EUA, especialmente dos jornais Chicago Defender, fundado em 1905, o maior jornal da imprensa negra norte-americana, e do New York Amsterdam News, fundado em 1909 em Nova Iorque - ambos ainda em circulação nos dias de hoje -, é possível observar aspectos dessa luta histórica por um currículo e uma educação que refletissem a experiência negra.

Desde o início do século XX até a década de 1960, tendo em vista um contexto de segregação racial, linchamentos e inferiorização da população negra naquela sociedade, em meio à luta contra o racismo e a desumanização das pessoas negras, constatamos majoritariamente nos referidos jornais a busca pelo ensino de História dos negros [Negro History, ou mais tarde Black History] para a própria população negra, como uma estratégia contra-hegemônica de afirmação, coletiva e individual, de sua humanidade e de seu valor, como algo que poderia elevar sua autoestima para ajudar a encarar as opressões racistas na sociedade norte-americana. Um bom exemplo, nesse sentido, é o artigo intitulado "Raça deve aprender mais sobre sua história, diz escritor que coloca a culpa no currículo escolar atual”, ${ }^{20}$ publicado em 9 de dezembro de 1939 no Chicago Defender, por John W. Tate Jr, que afirmava o seguinte: “O negro deve mesmo aprender a sua própria história se realmente deseja derrubar as cadeias do complexo de inferioridade que arrasta, ficar de pé e ser o homem que realmente é”. ${ }^{21}$ Questionando inclusive políticos e professores negros, o autor do artigo menciona as escolas negras, que chama de "o próprio berço da esperança negra”, mas que "são desviadas do seu verdadeiro propósito e distorcidas em coisas monstruosas”, já que "seus currículos têm formado escolas que servem como uma ajuda pobre, muito pobre, para a concretização da esperança”. ${ }^{22}$ Segundo John W. Tate Jr., nas escolas públicas de Chicago,

[...] os estudantes de cor são educados para serem brancos e, depois de alguns anos de instrução na arte, são empurrados para a corrente da vida e obrigados a voltar e ser um membro de um povo sobre o qual sabem pouco ou nada e cujos problemas eles entendem menos ainda. $\left(1939\right.$, p. 15) ${ }^{23}$

\footnotetext{
20 No original: "Race Must Learn More Of Its History Says Scribe Who Puts Blame On Present School Plan". Até meados da década de 1960, quando o uso do termo black ganha proeminência política na comunidade negra e passa a ser mais utilizado, especialmente a partir do movimento black power que buscava alistar a população negra para participar das eleições, era muito comum o uso dos termos race, people of color, colored ou negro para designar a população negra nos Estados Unidos.

21 No original: "The negro must learn the History of himself if he really wishes to throw down the dragging chains of inferiority complex, to stand erect and to be the man he in truth is."

22 No original: "The very cradle of Negro hope"; "are diverted from their true purpose and distorted into monstrous things"; "their curricula are now shaped schools serve as a poor, a very poor aid to the realization of the hope."

23 No original: "Colored students are educated to be white folk, and, after a few years of instructions in the art they are pushed into the stream of life and forced to return to and be one of a people about whom they know little or nothing and whose problems they understand less."
} 
A educação eurocêntrica, na qual alunos negros eram educados para serem brancos, que era alimentada e informada pelo racismo nas escolas norte-americanas, inclusive nas escolas criadas por negros, como problematizava o artigo citado, também era uma característica das escolas brasileiras no pós-abolição da escravidão e no início da República. Segundo o historiador Jerry Dávila, os dirigentes da educação pública brasileira do início do século XX "não impediram alunos de cor de frequentarem suas escolas”, ao contrário, eles "buscavam aperfeiçoar a raça - criar uma 'raça brasileira' saudável, culturalmente europeia, em boa forma física e nacionalista” (2006, p. 21). Por considerarem pobres e não brancos, em sua maioria, como degenerados, em termos raciais e culturais, ainda segundo Dávila, esses dirigentes da educação pública "definiram as escolas como clínicas em que os males nacionais associados à mistura das raças poderiam ser curados”, e, nesse sentido, "suas crenças forneceram um poderoso motivo para a construção de escolas e moldaram a forma como essas escolas funcionariam”, a partir do trabalho de educadores "dotados da incumbência de forjar um Brasil mais europeu e presos a um senso de modernidade vinculado à brancura” (2006, p. 22 e 25).

Assim como o eurocentrismo e o racismo são aqui compreendidos a partir de uma perspectiva transnacional, encontram-se muitas evidências do caráter transnacional da luta antirracista. A circulação dos jornais da imprensa negra na diáspora africana é exemplar, nesse sentido. Por meio dessa circulação, personagens como Booker T. Washington e Marcus Garvey tornavam-se importantes referências para negros brasileiros. ${ }^{24}$ Ainda durante a década de 1920 , por exemplo, O Clarim d'Alvorada, um dos mais importantes jornais da imprensa negra brasileira, que circulou entre 1924 e 1932, também publicava uma seção intitulada “O Mundo Negro”. Sobre esse fato, José Correia Leite, fundador e editor do jornal, disse o seguinte:

Certa vez, na redação d'O Clarim d'Alvorada, apareceu um
grupo de baianos que se prontificou a colaborar. [...] Por
intermédio deles, O Clarim d'Alvorada entrou em contato
com um poliglota, o Mário de Vasconcelos. E foi daí que co-
meçamos a conhecer melhor o movimento panafricanista, o
movimento do Marcus Garvey. Tudo por meio desse Mario
de Vasconcelos, porque lá da Bahia ele começou a mandar
colaboração já traduzida para o nosso jornal sobre o traba-
lho do movimento negro nos Estados Unidos e em outras
partes. [...] Nós fizemos uma seção dentro d'O Clarim d'Al-
vorada com o título "O Mundo Negro", que era justamente
o título do jornal que o Marcus Garvey tinha nos Estados
Unidos: "The Negro World". [...] O movimento garveysta

24 O jamaicano Marcus Garvey (1887-1940) fundou a Universal Negro Improvement Association e a African Communities League. Estabelecendo-se nos Estados Unidos, chegou a fundar uma companhia de navegação em 1919, a Black Star Line Steamship Corporation, para promover o transporte dos afrodescendentes para a África. A empresa, contudo, foi processada por irregularidades, e Garvey foi deportado para a Jamaica. Em 1935, fixou-se em Londres, onde faleceu. 
entre nós ficou restrito, mas serviu para tirar certa dubiedade do que nós estávamos fazendo. [...] As idéias do Marcus Garvey vieram reforçar as nossas. Com elas nós criamos mais convicção de que estávamos certos. Fomos descobrindo a maneira sutil do preconceito brasileiro, a maneira de como a gente era discriminado. (LEITE, 1992, p. 77-78, 80-81)

John W. Tate Jr. terminou seu artigo no Chicago Defender, em 9 de dezembro de 1939, com a seguinte afirmação: "Estude a história do negro - que este seja o lema do negro atual! E deixe-o estudar cientificamente estudando as biografias de seus grandes homens". ${ }^{25}$ Essa estratégia, indicada pelo autor do artigo, era algo também muito comum na imprensa negra do Brasil no início do século XX: o conhecimento em relação às biografias de grandes homens negros. Com isso, fica muito evidente a questão de gênero nos jornais pesquisados. Tanto nos EUA quanto no Brasil, os jornais apresentam os grandes homens negros de maneira muito mais frequente do que grandes mulheres negras. Entretanto, ao longo das pesquisas em várias edições do jornal 0 Clarim d'Alvorada, encontra-se uma celebração à figura da Mãe preta, fato que já foi analisado por historiadoras. ${ }^{26}$ Nesse mesmo jornal, há uma constante celebração dos grandes homens negros brasileiros, como José do Patrocínio [1854-1905], jornalista, editor e importante abolicionista; Cruz e Souza [1861-1898], um dos maiores poetas brasileiros; e, sobretudo, Luiz Gama [1830-1882], jornalista e poeta abolicionista que, atuando na Justiça como advogado, mesmo sem formação acadêmica, conseguiu libertar mais de 500 pessoas negras da escravidão. Todavia, na edição do jornal 0 Clarim d'Alvorada de 20 de dezembro de 1931, na seção “O Mundo Negro”, que tinha como manchete principal "Eduquemos nosso Povo”, ao apresentar ao leitor uma Cartilha da História Negra escrita nos EUA, entre vários homens negros norte-americanos, como "George Carver, o mais competente chimico agrícola do Sul”, o jornal dava destaque para duas mulheres negras: "Phyllis Wheatley [1753-1784], filha de escravos africanos, que escreveu poesias tão famosas a ponto de ser cumprimentada pelo presidente Washington e regalada pela orgulhosa realeza inglesa”, e "Mary McLeod Bethune [1875-1955], que com intelligencia e perseverança construiu uma escola para meninas negras em Dayton, Florida”.

Um marco fundamental para o desenvolvimento dessa estratégia contra-hegemônica na luta antirracista, por meio do conhecimento e do ensino da História dos negros, foi a Negro History Week [Semana da História Negra], criada em 1926 pelo historiador negro norte-americano Carter G. Woodson, que tinha o objetivo de relembrar e manter viva a importância de pessoas e eventos na história da população negra na diáspora africana. Originalmente, a Semana da História Negra era realizada na segunda semana de fevereiro, em função da celebração do 
nascimento de Abraham Lincoln, em 12 de fevereiro, e de Frederick Douglass, ${ }^{27}$ em 14 de fevereiro, respectivamente celebrando a abolição da escravidão decretada pelo presidente Lincoln e a luta abolicionista representada pelo grande líder negro Frederick Douglass. Para Abul Pitre, Ruth Ray e Esrom Pitre:

\begin{abstract}
A Semana da História do Negro de Woodson foi um passo importante no processo de erradicar muitos dos problemas que confrontam os afro-americanos como resultado da instituição da escravidão. Alguns desses problemas incluem falta de educação significativa, autoconhecimento e autoestima. A ideia da História Negra provocou controvérsia desde a sua criação e continua a ser uma questão importante na arena educacional. Os oponentes da ideia argumentaram que sua implementação no currículo seria desonesta, divisiva e faria com que as crianças ficassem mal preparadas para o mundo do trabalho. Os proponentes da História Negra acreditam que ela promoverá a diversidade cultural, desenvolverá a autoestima e corrigirá muitos dos mitos adotados pelo currículo eurocêntrico. Carter G. Woodson foi confrontado com muitos dos argumentos atuais que tentaram manter a História Negra fora do currículo. ${ }^{28}$ (PITRE; RAY; PITRE, 2008, p. 15)
\end{abstract}

Já a partir de meados da década de 1960, na imprensa negra norte-americana, chama a atenção uma mudança de perspectiva em relação à luta antirracista na área da educação e especificamente nos currículos e no ensino de História. Como consequência dos avanços na luta pelos direitos civis para a população negra, a partir do início do processo de integração das escolas públicas antes racialmente segregadas e do início das primeiras políticas de ação afirmativa para negros naquele contexto nacional, observa-se na imprensa negra estadunidense não mais uma ênfase na História dos negros para os próprios negros nas escolas exclusivamente negras, mas inicia-se um processo de luta pela integração da História negra nos currículos de todas as escolas públicas naquele país.

Esse processo continua em curso, como já foi dito anteriormente. Mas dois exemplos, relativamente recentes, são marcantes no sentido de demonstrar que a discussão sobre a importância da História negra na educação pública está na agenda de debates nos Estados Unidos: o feriado nacional do dia de Martin Luther

27 Frederick Douglass (1818-1895), nascido filho de uma mulher escravizada e de um homem branco, conseguiu libertar-se da escravidão com 20 anos, por meio dos estudos. Foi um importante escritor e o abolicionista negro norte-americano mais reconhecido em sua época.

28 No original: "Woodson's Negro History Week was a major step in the process of eradicating many of the problems that confront African Americans as a result of the institution of slavery. Some of those problems include lack of meaningful education, self-knowledge, and self-esteem. The idea of Black History has stirred controversy since its inception and continues to be an important issue in the educational arena. Opponents of the idea have argued that its implementation into the curriculum will be dishonest, divisive, and will make children ill-prepared for the work force. Proponents of Black History believe that it will promote cultural diversity, develop self-esteem, and correct many of the myths espoused by the Euro-centric curriculum. Carter G. Woodson was confronted with many of the current arguments that attempted to keep Black History out of the curriculum." 
King Jr., ${ }^{29}$ que é celebrado na terceira segunda-feira do mês de janeiro em todo o país desde 1986; e a construção do Black History Month [Mês da História Negra], celebrado durante todo o mês de fevereiro e que foi criado em 1976, durante as comemorações pelos 200 anos dos Estados Unidos da América. O Black History Month tem sua raiz na Negro History Week, já mencionada.

Ao longo das pesquisas nos jornais da imprensa negra norte-americana, encontram-se diversas reportagens desde a década de 1920 sobre a Negro History Week e sua importância para a população negra. Um exemplo emblemático é a matéria intitulada "Por que nós devemos estudar a História negra" [Why We Should Study Negro History], publicada no Chicago Defender de 19 de fevereiro de 1966, escrita por Jill D. Pilate, um menino negro de 10 anos de idade e aluno do ensino fundamental em uma escola pública de Chicago. Nessa matéria, Jill elenca algumas razões para que negros estudem suas próprias histórias, razões muito semelhantes àquelas apresentadas no artigo no mesmo jornal em 1939, conforme citado. Contudo, se antes o conhecimento da História negra era fundamental para a afirmação de sua humanidade, de sua autoestima, para ficar de pé e com orgulho de "ser o homem que realmente é", chama a atenção no texto de um menino tão jovem a afirmação de que "ter orgulho e proclamar o trabalho de nossos antepassados não é suficiente". ${ }^{30}$ Jill continua seu texto, escrito para a Negro History Week de 1966, numa escola pública de Chicago, evidenciando seu desejo pelo avanço nos estudos e pela igualdade e integração entre as raças, afirmando que "devemos preparar nossas mentes e nossos corpos para aproveitar ao máximo todas as oportunidades para o ensino superior. Precisamos preparar nossos corações para amar e viver com todos os homens". ${ }^{31}$

Em outra reportagem do Chicago Defender, publicada em 19 de outubro de 1968, intitulada “Ativista quer História Negra integrada” [Activist Wants Black History Integrated], Meyer Weinberg afirmava que "a História negra não deveria estar separada nos livros didáticos ou nas salas de aula", na medida em que "as realizações históricas e o trabalho da América negra não podem ser entendidos como reflexões ou notas de rodapé da História branca”. ${ }^{32}$ Ao contrário, segundo Weinberg, "a experiência negra deve ser vista como uma característica central da História americana”. Para ele, "os historiadores brancos não só falharam em incluir os negros, mas eles não têm contado a História dos EUA como ela é”. ${ }^{33} \mathrm{~A}$ perspectiva demonstrada nessa reportagem, que buscava a integração não somente das pessoas de diferentes raças nas escolas, mas também das histórias a serem ensinadas para toda a população, em termos de igualdade, sem as hierarquias

29É interessante notar que há somente três feriados nacionais nos EUA em homenagem a indivíduos que foram personagens históricos. São os feriados em homenagem ao próprio Martin Luther King Jr., a George Washington, considerado o principal "pai" da nação, e a Cristóvão Colombo, o "descobridor" da América.

30 No original: "being proud and proclaiming the works of our forefathers isn't enough."

31 No original: "we must prepare our minds and our bodies to make the most of every opportunity for higher education. We must prepare our hearts to love and live with all men."

32 No original: "Negro history should not be separate in textbooks or in classrooms"; "the historical achievements and travail of black America cannot be understood either as afterthoughts or footnotes to white history."

33 No original: "The Negro experience must be seen as a central feature of American history"; "white historians have not only failed to include Negroes, but they have not told the U.S. history like it was." 
influenciadas pelo racismo, em meio às lutas pelos direitos civis, ganha importância na luta antirracista na segunda metade do século XX na diáspora africana.

É interessante notar, por exemplo, que, durante o I Congresso de Cultura Negra das Américas, realizado em Cali, na Colômbia, em agosto de 1977, foi elaborada uma lista com algumas recomendações que foram aprovados na plenária do Congresso. Uma segunda recomendação aprovada foi: "Reescrever a História do negro para mostrar sua autêntica participação na construção da América e programar sua difusão na Educação primária, secundária, universitária e familiar”. ${ }^{34}$ A própria manchete da Seção Afro-Latino-América da revista Versus, que apresentava as informações sobre o referido Congresso, estampava a frase "Contra o racismo, por uma nova História”, em letras garrafais. A participação de lideranças negras brasileiras nesse congresso foi intensa. Abdias do Nascimento, ${ }^{35}$ que em 1982 organizaria o terceiro e último Congresso de Cultura Negra das Américas, em São Paulo, foi uma das lideranças brasileiras que mais influenciou nos debates do I Congresso, inclusive tendo algumas de suas demandas inseridas entre as recomendações aprovadas na plenária do Congresso. Segundo reportagem da Seção Afro-Latino-América na revista Versus n. 15, de outubro de 1977, Abdias teria sido o responsável pela denúncia da tentativa de criação do “Tratado do Atlântico Sul”, entre o governo racista da África do Sul e as ditaduras do Brasil, Chile e Argentina. Essa denúncia, a ser levada à Organização das Nações Unidas, tornou-se outra das recomendações aprovadas, pois para os participantes do Congresso esse suposto Tratado do Atlântico Sul seria "efetivamente um pacto contra os nacionalistas negros". Outra recomendação aprovada foi a seguinte: "Visando erradicar todas as formas de colonização, inclusive a linguística, propor aos órgãos educativos dos países da América o ensino de uma língua africana para servir de educação e comunicação universal entre os negros de todo o mundo". ${ }^{36}$ Vinte anos mais tarde, quando senador da República no Brasil, Abdias do Nascimento apresentou o Projeto de Lei do Senado (PLS) n. 75, de 24 de abril de 1997, que dispunha sobre as medidas de ação compensatória para a implementação do princípio da isonomia social do negro e incluía no ensino dos idiomas estrangeiros, em regime opcional, as línguas iorubá e kiswahili. Fica evidente, ao analisar essas fontes históricas, a importância dada à educação por parte das lideranças negras na luta antirracista nas Américas.

No Brasil, a própria Carta de Princípios de uma das mais importantes organizações do movimento negro brasileiro, criada em 1978 na luta contra a ditadura civil-militar, o Movimento Negro Unificado (MNU), redigida ainda em 1978,

\footnotetext{
34 Seção Afro-Latino-América da Revista Versus, n. 15, p. 34-35, out. 1977.

35 Abdias do Nascimento (1914-2011) nasceu em Franca (SP), fundou o Teatro Experimental do Negro, em 1944, e foi um dos organizadores da Convenção Nacional do Negro, encontro realizado por dois anos (1945 e 1946), no Rio e em São Paulo, que propôs à Constituinte de 1946 a tipificação da discriminação racial como crime de lesa-pátria. Participou também como organizador do primeiro Congresso do Negro Brasileiro, em 1950. Em 1968 exilou-se nos Estados Unidos em decorrência do endurecimento do governo militar, no poder desde abril de 1964, e foi professor em diversas universidades norte-americanas. Participou da fundação do Movimento Negro Unificado, em 1978, e criou, em 1981, o Instituto de Pesquisas e Estudos Afro-Brasileiros na Pontifícia Universidade Católica (PUC) de São Paulo. Foi deputado federal pelo Rio de Janeiro entre 1983 e 1986 e senador pelo mesmo estado de 1991 a 1992 e de 1997 a 1999. 
apresentava a reivindicação que se tornou uma característica desse movimento social na contemporaneidade: a luta "pela reavaliação do papel do negro na história do Brasil”. Assim, a estratégia de ir às escolas, de produzir conhecimento, por meio inclusive da elaboração de materiais didáticos, e de influenciar o trabalho de professores nas escolas públicas, sobretudo na área de história, tornou-se muito recorrente em diferentes estados a partir do final da década de 1970 e início dos anos de 1980 (PEREIRA, 2012). Esses esforços e estratégias do movimento negro no Brasil, em meio ao processo de disputas em torno do currículo escolar durante a redemocratização do país na década de 1980, resultaram em algumas importantes conquistas, como o parágrafo $1^{\circ}$ do art. 242 da Constituição Federal de 1988, que já determinava que "o ensino da História do Brasil levará em conta as contribuições das diferentes culturas e etnias para a formação do povo brasileiro". ${ }^{37}$

Nos EUA, por sua vez, também a partir da década de 1970 e especialmente nos anos de 1980, encontram-se muitos esforços semelhantes, no sentido de incorporar as histórias das populações negras no ensino de História e na educação de maneira mais ampla. Um bom exemplo, no estado de Nova Iorque, é a reportagem do New York Amsterdam News, de 2 de julho de 1983, intitulada "É urgente o ensino da História negra em escolas públicas" [Urges teaching of Black history in public schools], na qual o senador estadual ${ }^{38}$ William Boyland, um político negro que representava o distrito do Brooklyn, discutia o projeto de lei que apresentou no Senado Estadual de Nova Iorque autorizando "a Secretaria de Educação do Estado a incluir a História negra no currículo das escolas públicas" ${ }^{39}$ Essa reportagem de 1983, de certa maneira, sintetiza aspectos apontados nas matérias já citadas, publicadas pela imprensa negra dos EUA, mas, ao discutir um projeto de lei elaborado e apresentado por um político negro, avança na perspectiva apontada na reportagem citada, do Chicago Defender de 1968, que buscava a integração da História negra na História dos Estados Unidos, bem como já buscava o ensino dessa História negra para todas as crianças e jovens, negros e brancos. Na década de 1980, William Boyland defendia essa perspectiva ao falar da "necessidade de cursos de História negra nas escolas públicas”, pois todos os “jovens deveriam estar familiarizados com as enormes contribuições que os negros têm produzido econômica, social, educacional e culturalmente". ${ }^{40}$ Segundo Boyland, a lei que propunha não criaria um novo curso de História, mas garantiria que a História negra fosse incluída no curso de História dos Estados Unidos na oitava série do ensino fundamental nas escolas públicas de Nova Iorque, o que "beneficiaria estudantes negros e brancos das escolas públicas ao oferecer-lhes uma educação completa”, já que ainda, segundo ele, “a História negra, não é ensinada em muitas

\footnotetext{
37 Sobre a pressão do movimento negro para a entrada desse artigo na Constituição Federal de 1988, ver a tese de doutorado em História de Mírian Garrido (2017).

38 Equivalente a deputado estadual no Brasil.

39 No original: "The State Education Department to include Black History in the public school curriculum."

40 No original: "There is a need for Black History courses in public school"; "Young people should be acquainted to the enormous contributions that Blacks have made economically, socially, educationally and culturally."
} 
escolas públicas”. E sem a História negra, “a História dos Estados Unidos não é ensinada corretamente", dizia ele. ${ }^{41}$

Chama a atenção na reportagem citada o posicionamento de Ron Frantz, um representante da Associação dos Professores do Estado de Nova Iorque, que, embora reconheça o projeto de lei como bom, diz que a associação não se posicionou em relação à legislação proposta porque estariam desconfortáveis com ela, já que, segundo ele, "não sentimos que a legislação deva envolver-se em ditar os currículos das escolas". ${ }^{42}$ Argumentos como esse são ouvidos ainda hoje tanto nos EUA como no Brasil. O fato é que nos EUA nunca uma legislação como essa, proposta em 1983, foi aprovada, nem mesmo em âmbito estadual. Vale ressaltar que nos EUA o sistema de educação é bem diferente, em comparação ao do Brasil, pois os diferentes estados da federação têm muito mais autonomia para gerir suas políticas educacionais, inclusive no que diz respeito aos currículos escolares. ${ }^{43}$

Como uma forma de lidar com as demandas da população negra em torno do ensino da História negra nas escolas públicas, após muitas e diversas lutas empreendidas pelo movimento negro nos EUA, em alguns estados, como Nova Jersey, Illinois e Nova Iorque, foram criadas comissões, no âmbito das secretarias estaduais de Educação, para "revisar como a história afro-americana e os 250 anos de escravidão são ensinados nas salas de aula dos EUA". ${ }^{44}$ Nesses três estados, não por acaso, o nome da comissão é o mesmo: Amistad Commission, em função da importância da história da luta dos negros que tomaram o navio Amistad em 1839, foram parar na cidade de New Haven e fizeram com que essa história se tornasse um símbolo da luta por liberdade da população negra nos EUA, como já dito. Criada em 2005, pelo mesmo Senado Estadual no qual, em 1983, William Boyland havia proposto o projeto de lei mencionado, segundo o seu site:

A Amistad Commission do Estado de Nova lorque está encarregada de pesquisar e avaliar até que ponto o comércio de escravos africanos, a escravidão americana e suas consequências e legados estão incluídos nos currículos das escolas estaduais de Nova lorque; e fazer recomendações ao Governador e ao Poder Legislativo sobre a implementação de programas de educação e conscientização nos currículos escolares. A Comissão se concentrará nas contribuições dos afro-americanos na construção de nosso país, na história americana, incluindo abolicionistas, movimentos de direitos

41 No original: "would benefit Black and white public school children by giving them a 'complete' education"; "Black history is not taught in many public schools"; "American history is not being taught correctly." New York Amsterdam News, 2 de julho de 1983, p. 25

42 No original: "We do not feel legislation should become involved in dictating curriculums for schools." New York Amsterdam News, 2 de julho de 1983, p. 25

$43 \cup \mathrm{m}$ exemplo interessante, nesse sentido, é o fato de que há estados norte-americanos que, nos dias de hoje, em função de leis estaduais, ainda ensinam o criacionismo nas escolas, como é o caso do estado do Tennessee, que passou a permiti-lo em 2012. Disponível em: https://exame.abril.com.br/ciencia/estado-dos-eua-aprova-ensino-do-criacionismo-nas-escolas/. Acesso em: 1 jun. 2018

44No original: "to review how African American history and 250 years of slavery is taught in America's classrooms." Disponível em: https://www.dos.ny.gov/amistad/about.html. Acesso em: 1 jun. 2018 
civis e outros desenvolvimentos para criar uma maior conscientização sobre o envolvimento da nação na escravidão para inspirar o reconhecimento e o diálogo informado. ${ }^{45}$

A Amistad Commission de Nova Iorque, portanto, tem a prerrogativa de revisar os currículos escolares implementados nos distritos do estado e, no máximo, sugerir possíveis mudanças. Ela não tem o poder de transformar o trabalho que é realizado nas escolas. Embora seja uma conquista, resultado da pressão política exercida pelo movimento negro, sua estrutura é muito frágil e pouco eficiente em termos de atuação direta nos distritos e nas escolas. Ao longo das pesquisas em Nova Iorque, entre fevereiro e maio de 2016, entrevistei três professores de História em escolas públicas do distrito do ex-deputado William Boyland, o Brooklyn, e nenhum deles havia tido contato com o trabalho feito pela Amistad Commission no estado ou mesmo em suas escolas. Segundo o relatório de 2009-2010 da Comissão, a que tive acesso em 2016, quando o recebi das mãos do professor Fredrick Harris, que à época era um dos seus 19 membros, a Amistad Commission reuniu-se somente quatro vezes entre março de 2009 e janeiro de 2010. As suas três subcomissões - a de Recursos, a de Ensino Superior e a de Educação Básica - reuniram-se cinco vezes cada, entre agosto de 2009 e janeiro de 2010, para desenvolver recomendações. O fato é que os currículos pouco foram alterados em função da existência da Amistad Commission no estado, desde o ano de 2005. Um exemplo, nesse sentido, é o resultado de uma pesquisa realizada pela própria Comissão com funcionários, administradores, pais de alunos e professores, entre outros trabalhadores, num total de 269 respondentes, de todos os distritos do estado de Nova Iorque, e divulgada no relatório de 2010: quando perguntados sobre “Qual opção melhor descreve com que frequência os professores em seu distrito exploram as histórias dos negros em suas aulas (pode escolher mais de uma resposta)", entre oito opções de respostas, a opção mais escolhida, com 36,4\%, foi "Somente durante o mês da História Negra”; e, em segundo lugar, com $21,9 \%$, foi a opção "Raramente". ${ }^{4}$

Já no Brasil, conscientes desse campo de batalhas, dessa arena política e cultural que é o currículo, militantes do movimento negro, especialmente a partir da década de 1980, buscaram formas de intervir no campo educacional e obtiveram algumas importantes conquistas, inclusive chegando a intervir na elaboração de políticas e documentos curriculares oficiais, como os Parâmetros Curriculares Nacionais (PCN) publicados em 1998 (PEREIRA, 2012), ou mesmo fazendo parte de processos políticos que levaram à construção de legislação ou de

45 No original: "New York State's Amistad Commission is charged with researching and surveying the extent to which the African slave trade, American slavery and its aftermath and legacy is included in the curricula of New York state schools; and make recommendations to the Governor and Legislature regarding the implementation of education and awareness programs into schools curricula. The Commission will focus on the contributions of African-Americans in building our country, American History including Abolitionists, Civil Rights movements and other developments to create a greater awareness about the nation's involvement in slavery to inspire acknowledgement and informed dialogue. Disponível em: https://www.dos.ny.gov/amistad/about.html. Acesso em: 1 jun. 2018.

46 Final Report of the Amistad Commission: New York State Department of Education, New York State Department of State, Winter, p. 14, 2010 
políticas públicas que pudessem possibilitar a busca da "reavaliação do papel do negro na História do Brasil”. O mais importante exemplo que tem possibilitado a construção de espaços de enunciação das diferenças e a "instabilidade produtiva de mudança cultural” (BHABHA, 1998, p. 68), em escolas de todos o país e na sociedade brasileira como um todo, foi a criação da Lei n. 10.639/2003, que alterou a Lei de Diretrizes e Bases da Educação Nacional (LDB) de 1996 e tornou obrigatório o ensino de História e culturas africanas e afro-brasileiras nas escolas de todo o país. A Lei n. 10.639/2003 teve em sua construção a ação direta de militantes do movimento negro (PEREIRA, 2017). Vale ressaltar ainda que as Diretrizes Curriculares Nacionais para a Educação das Relações Étnico-Raciais, publicadas em 2004, tiveram como relatora uma intelectual negra indicada pelo movimento negro para compor o Conselho Nacional de Educação (CNE) entre 2002 e 2006, a professora Petronilha Beatriz Gonçalves e Silva.

Ao longo das pesquisas, cada vez mais tenho entendido que as ações do movimento negro transnacional no âmbito da educação, seja no Brasil ou nos Estados Unidos, mesmo com diferenças, partem da compreensão de que o eurocentrismo e o racismo se retroalimentam no contexto educacional, num ciclo vicioso que inviabiliza a construção de uma perspectiva realmente democrática nos currículos e na educação. Democracia, nos currículos e nas escolas, pressupõe participação e representação de todos os envolvidos no processo educativo. Na medida em que o eurocentrismo alimenta o racismo e dificulta que memórias e histórias das populações negras estejam presentes nos currículos e no ensino de História, inviabiliza-se o desenvolvimento de uma perspectiva democrática no processo educativo. Nesse sentido, no Brasil, a Lei n. 10.639/2003, ao problematizar o tradicional eurocentrismo na educação brasileira, tem um potencial de mudança cultural ao ser implementada com qualidade acadêmica e compromisso político com uma educação antirracista e democrática.

Em pesquisa feita entre 2011 e 2015 com professores de História em escolas públicas da cidade do Rio de Janeiro e da Baixada Fluminense, por meio de 22 entrevistas de história oral realizadas, chamou a atenção o fato de que todos os professores entrevistados conheciam a Lei n. 10.639/2003. Esse parece ser um dado bastante positivo (PEREIRA; LIMA, 2016). Entretanto, nessa mesma pesquisa, foi constatado também o fato de que muitos professores acreditam estar realizando

[...] a implementação da legislação mencionada ao, somente na semana de 20 de Novembro, celebrar em alguma atividade escolar o "Dia Nacional da Consciência Negra", que inclusive consta oficialmente no calendário das escolas brasileiras; ${ }^{47}$ ou, por outro lado, apresentar alguma discussão sobre a escravidão no Brasil durante a semana do dia 13 de 
Observa-se, assim, mais uma semelhança entre contextos sociais do Brasil e dos Estados Unidos, no que se refere às dificuldades relacionadas ao ensino das histórias das populações negras, na medida em que muitos professores, lá e cá, entendem simplesmente que já seria suficiente trabalhar alguns aspectos dessas histórias em momentos específicos do ano, seja no Black History Month, seja na semana do Dia Nacional da Consciência Negra. A construção de currículos que apresentem as histórias e culturas de todas as matrizes formadoras da sociedade, considerando-as todas importantes e complementares, sem o tradicional eurocentrismo mencionado, é algo fundamental para a formação de cidadãos com identidades individuais e sociais diversas, que aprendam a respeitar as diferenças e possam lidar de maneira positiva com a pluralidade cultural, para que seja possível a construção e consolidação de uma perspectiva democrática na educação nos diferentes contextos sociais.

\section{CONSIDERAÇÕES FINAIS}

Um importante elemento que deve ser levado em consideração nas análises sobre a formação e atuação dos diferentes movimentos sociais são as informações e referenciais que chegam até os militantes pelos meios de comunicação. Nesse sentido, a criação de seus próprios jornais, divulgando informações a partir de seus objetivos, historicamente foi uma estratégia fundamental. No caso do movimento negro brasileiro e do estadunidense, essa estratégia foi utilizada nos diferentes momentos de sua história, desde a primeira metade do século XIX, como se viu anteriormente. Veículos de informação constituídos por negros tiveram um papel fundamental para a circulação de informações, ideias e referenciais para a luta contra o racismo no Brasil, nos EUA e em outras partes do planeta. As reivindicações e denúncias feitas pela população negra em relação à educação e ao ensino de História, tanto nos EUA quanto no Brasil, foram muitas e também influenciavam a própria dinâmica das lutas realizadas.

Muitas “estratégias contra-hegemônicas” de luta e muitas "histórias emergentes” foram divulgadas e debatidas por meio dos jornais da imprensa negra, em diferentes contextos nacionais. A circulação dessas estratégias e histórias na imprensa criada e conduzida pela população negra, em articulação com a luta política antirracista transnacional liderada pelo movimento negro, foi fundamental para que "valentes guerreiras” pudessem sair para "recuperar” a Nossa história, "a limpar suas lágrimas, suas mãos, a vesti-la de novo, enchê-la de orgulho, lavar seus joelhos”, como diz a poesia que abre este artigo. O trabalho com essa história nas escolas, “com o peito erguido e a cabeça alta”, imbuídos de uma perspectiva democrática na construção dos currículos escolares, um currículo no qual "todas as vidas importem" igualmente, continua sendo um grande desafio em sociedades tão desiguais racialmente e tão distintas quanto a brasileira e a norte-americana. 


\section{A luta contra o racismo é a mesma, lá e cá. Luta essa que, diante das contingências e possibilidades de cada diferente realidade social, é sempre um fato cultural e um fator de cultura, como diria Amilcar Cabral.}

\section{REFERENCIAS}

ABUD, Katia Maria. A História nossa de cada dia: saber escolar e saber acadêmico na sala de aula. In: MONTEIRO, Ana Maria; GASPARELLO, Arlette Medeiros, MAGALHÃES, Marcelo de Souza (org.). Ensino de História: sujeitos, saberes e práticas. Rio de Janeiro: Mauad X, Faperj, 2007. p. 107-117.

ALBERTO, Paulina. A mãe preta entre sentimento, ciência e mito: intelectuais negros e as metáforas cambiantes da inclusão racial, 1920-1980. In: GOMES, Flávio dos Santos; DOMINGUES, Petrônio (org.). Políticas da raça: experiências e legados da abolição e da pós-emancipação no Brasil. São Paulo: Selo Negro, 2014.

ALLEN, James. Pioneer Efforts In Education For Blacks. New York Amsterdam News, 12 de junho de 1971.

BARR, Shirley Campbell. Rotundamente negra y otros poemas. Madrid: Torremozas, 2013.

BHABHA, Homi K. O local da cultura. Belo Horizonte: Ed. UFMG, 1998.

BITTENCOURT, Circe. Ensino de História: fundamentos e métodos. São Paulo: Cortez, 2004.

BITTENCOURT, Circe. Identidades e ensino de História no Brasil. In: CARRETERO, Mario (org.). Ensino de História e memória coletiva. Porto Alegre: Artmed, 2007.

CABRAL, Amilcar. PAIGC: Unida e Luta. Lisboa: Nova Aurora, 1974.

CUNHA, Olívia Maria Gomes da. 1933: um ano em que fizemos contatos. Revista USP, São Paulo, v. 28, p. 12-163, dez./fev. 1995/1996.

DÁVILA, Jerry. Diploma de brancura: política social e racial no Brasil: 1917-1945. São Paulo: Editora Unesp, 2006.

FANON, Frantz. Os condenados da terra. Juiz de Fora: Editora UFJF, 2005.

FERREIRA, Higor Figueira. A construção do currículo em uma experiência escolar para meninos pretos e pardos na Corte em meados do século XIX. 2013. Dissertação (Mestrado em Educação) - Universidade Federal do Rio de Janeiro, Rio de Janeiro, 2013.

GARRIDO, Mírian. Nas constituições dos discursos sobre afro-brasileiros: uma análise histórica da ação de militantes negros e dos documentos oficiais voltados a promoção do negro brasileiro (1978 a 2010). 2017. Tese (Doutorado em História) - Universidade Estadual Paulista “Júlio de Mesquita Filho”, Assis, 2017.

HANCHARD, Michael. Política transnacional negra, antiimperialismo e etnocentrismo para Pierre Bourdieu e Loïc Wacquant: exemplos de interpretação equivocada. Estudos Afro-Asiáticos, Rio de Janeiro, v. 24, n. 1, p. 63-96, 2002.

HOLLANDA, Sérgio Buarque de. Raízes do Brasil. 26. ed. São Paulo: Companhia das Letras, 1995.

LE GOFF, Jacques. Memória. In: Enciclopédia Einaudi. v. I Memória-História. Lisboa: Imprensa Nacional-Casa da Moeda, 1984.

LEITE, José Correia. ...E disse o velho militante José Correia Leite: depoimentos e artigos. Organização e textos: CUTI (Luiz Silva). São Paulo: Secretaria Municipal de Cultura, 1992.

MOREIRA, Antonio Flavio B.; SILVA, Tomaz Tadeu da (org.). Currículo, cultura e sociedade. São Paulo: Cortez, 2002. 
NADAI, Elza. O ensino de História no Brasil: trajetória e perspectiva. Revista Brasileira de História, São Paulo, v. 13, n. 25/26, p. 143-162, set. 1992/ago. 1993.

PEREIRA, Amilcar A. Por uma autêntica democracia racial!: os movimentos negros nas escolas e nos currículos de história. Revista História Hoje, São Paulo, v. 1, n. 1, p. 111-128, 2012.

PEREIRA, Amilcar A. O mundo negro: relações raciais e a constituição do movimento negro contemporâneo no Brasil. Rio de Janeiro: Pallas/Faperj, 2013.

PEREIRA, Amilcar A. O movimento negro brasileiro e a lei n. 10639/2003: da criação aos desafios para a implementação. Revista Contemporânea de Educação, Rio de Janeiro, v. 12, n. 23, p. 13-30, jan./abr. 2017.

PEREIRA, Amilcar A.; LIMA, Thayara S. de. Isso não é História? Professores de História no Rio de Janeiro entre perspectivas e narrativas nacionais e locais sobre História e Cultura Afro-Brasileiras. In: GABRIEL, Carmen T.; MONTEIRO, Ana Maria; MARTINS, Marcus L. B. (org.) Narrativas do Rio de Janeiro nas aulas de História. Rio de Janeiro: Mauad X, 2016. p. 107-128.

PITRE, Abul; RAY, Ruth; PITRE, Esrom. The struggle for Black History: Foundations for a Critical Black Pedagogy in Education. Lanham, MD: University Press of America, 2008.

POLLAK, Michael. Memória e Identidade Social. Estudos Históricos, Rio de Janeiro, v. 5, n. 10, p. 200-212, 1992.

SIEGEL, Micol. Mães pretas, filhos cidadãos. In: CUNHA, Olívia Maria Gomes da; GOMES, Flávio dos Santos (org.). Quase-cidadão: histórias e antropologias da pós-emancipação no Brasil. Rio de Janeiro: Editora FGV, 2007.

SILVA, Tomaz Tadeu. Documentos de identidade: uma introdução às teorias do currículo. Belo Horizonte: Autêntica, 2007.

TATE JR., John W. Race Must Learn More Of Its History Says Scribe Who Puts Blame On Present School Plan. Chicago Defender, em 9/12/1939, p. 15.

WATKINS, William. Blacks and the curriculum: from accommodation to contestation and beyond. In: WATKINS, William; LEWIS James H.; CHOU, Victoria (ed.). Race and education: the roles of history and society in educating African American students. Needham Heights, MA: Allyn \& Bacon, 2001. p. 40-65.

\section{COMO CITAR ESTE ARTIGO}

PEREIRA, Amilcar Araujo. Black lives matter nos currículos? imprensa negra e antirracismo em perspectiva transnacional. Cadernos de Pesquisa, São Paulo, v. 49, n. 172, p. 122-143, abr./jun. 2019. https://doi.org/10.1590/198053145589 